\title{
Pressure and Temperature Dependence of the Longitudinal Deuterium Relaxation Times in Supercooled Heavy Water to $300 \mathrm{MPa}$ and $188 \mathrm{~K}$
}

\author{
E. Lang and H.-D. Lüdemann
}

Institut für Biophysik und Physikalische Biochemie, Universität Regensburg, Postfach 397, D-8400 Regensburg

Flüssigkeiten / Hohe Drücke / Magnetische Kernresonanz / Transporterscheinungen / Zwischenmolekulare Wechselwirkungen

The longitudinal deuteron relaxation times $T_{1}$ in heavy water have been determined at $15.4 \mathrm{MHz}$ in the temperature range from $T=28.3 \mathrm{~K}$ $10188 \mathrm{~K}$ and up to pressures of $300 \mathrm{MPa}$. Between $283 \mathrm{~K}$ and $200 \mathrm{~K}$ all isotherms exhibit pronounced maxima of $T_{1}$ in the pressure range between $150 \mathrm{MPa}$ and $300 \mathrm{MPa}$. This maximum is most pronounced in the $242 \mathrm{~K}$ isotherm, where $T_{1}$ increases more than fourfold from $17 \mathrm{~ms}$ at $0.1 \mathrm{MPa}$ to $73 \mathrm{~ms}$ at $250 \mathrm{MPa}$. The $225 \mathrm{MPa}$ isobar runs at $192 \mathrm{~K}$ through a minimum: $T_{1}=0.5 \mathrm{~ms}$. Under the assumption of isotropic reorientation one derives from the minimum condition $\left(\omega_{0} \cdot \tau_{0} \simeq 0.62\right)$ the deuteron quadrupole coupling constant for $\mathrm{D}_{2} \mathrm{O}$ to $C_{\mathrm{DQC}}=214 \pm 12 \mathrm{kHz}$. The isobaric temperature dependence of the correlation times $\tau_{\mathrm{B}}$ can be described at $p \geq 200 \mathrm{MPa}$ by the VTF equation. At $p \leq 100 \mathrm{MPa} \tau_{\theta}$ increases faster with falling temperature than predicted by the VTF-equation. In this range the isobars are best represented by an equation proposed by Speedy and Angell:

$$
\tau_{\theta}=\tau_{0}\left(\frac{T-T_{s}}{T_{s}}\right)^{\cdots}
$$

The determination of $\tau_{\theta}$ permits an estimate of the viscosity $\eta$ and the self-diffusion coefficient $D$ for $\mathrm{D}_{2} \mathrm{O}$ in the supercooled range. Around $T=190 \mathrm{~K}$ and $p=225 \mathrm{MPa}$ one gets $\eta \simeq 4 \mathrm{~Pa} \cdot \mathrm{s}$ and $D \simeq 6 \cdot 10^{-9} \mathrm{~cm}^{2} / \mathrm{s}$.

Die Spin-Gitter-Relaxationszeiten $T_{1}$ der Deuteronen in schwerem Wasser wurden bei einer Meßfrequenz von $15.4 \mathrm{MHz}$ in einem Temperaturintervall von $283 \mathrm{~K}$ bis $188 \mathrm{~K}$ und Drücken bis $300 \mathrm{MPa}$ bestimmt. Die lsothermen zwischen $T=283 \mathrm{~K}$ und $T=200 \mathrm{~K}$ zeigen ausgeprägte Maxima bei Drücken zwischen $150 \mathrm{MPa}$ und $300 \mathrm{MPa}$. Am deutlichsten zeigt sich das Maximum in der Isotherme $T=242 \mathrm{~K}$ Die Relaxationszeit $T_{1}$ ändert sich entlang dieser Isotherme um den Faktor 4 von $17 \mathrm{~ms}$ bei $0.1 \mathrm{MPa}$ auf $73 \mathrm{~ms}$ bei $250 \mathrm{MPa}$. Die $225 \mathrm{MPa}$ Isobare durchläuft ein Minimum bei $T=192 \mathrm{~K}$ und $T_{1}=0.5 \mathrm{~ms}$. Wird isotrope Rotationsdiffusion zugrunde gelegt, so erhält man aus der Bedingung für das $T_{1}$-Minimum: (1) $\cdot \tau_{\theta} \simeq 0.62$ ohne weitere Annahme die Deuteronen Quadrupolkopplungskonstante $C_{\text {DQC }}=$ $214 \pm 12 \mathrm{kHz}$. Die isobare Temperaturabhängigkeit der Orientierungskorrelationszeit $\tau_{\theta}$ kann bei Drücken $p \geq 200 \mathrm{MPa}$ mit der VTF Gleichung beschrieben werden. Im Druckbereich $p \leq 100 \mathrm{MPa}$ wächst $\tau_{\theta}$ hingegen schneller. als die VTF-Gleichung vorhersagt. Eine von Speedy und Angell vorgeschlagene Gleichung liefert eine sehr gute Beschreibung der Temperaturabhängigkeit von $\tau_{\theta}$ in diesem Druckbereich:

$$
\tau_{\theta}=\tau_{0}\left(\frac{T-T_{\mathrm{s}}}{T_{\mathrm{s}}}\right)^{-\because}
$$

Die Bestimmung von $\tau_{\theta}$ ermöglicht eine Abschätzung der Viskosität $\eta$ und des Selbstdiffusionskoeffizienten $D$ im unterkühlten Bereich. Bei $T=190 \mathrm{~K}$ und $p=225 \mathrm{MPa}$ erhält $\operatorname{man} \eta \simeq 4[\mathrm{~Pa} \cdot \mathrm{s}]$ und $D \simeq 6 \cdot 10^{-9}\left[\mathrm{~cm}^{2} / \mathrm{s}\right]$.

\section{Introduction}

Liquid water can be readily supercooled after emulsification in a mixture of cycloalkanes and an emulsifier [1]. Kanno. Speedy, and Angell [2] studied in such emulsions the pressure dependence of the homogeneous nucleation temperature $T_{11}$ to $300 \mathrm{MPa}$ with the result. that $T_{11}$ follows the general trends observed for the melting pressure curve. except that the decrease of $T_{11}$ with pressure is much steeper than the decrease 
of the $T_{m}(p)$-curve. Fig. 1 gives a simplified version of this part of the phase diagrams of $\mathrm{H}_{2} \mathrm{O}$ and $\mathrm{D}_{2} \mathrm{O}$. The whole region between $T_{m}(p)$ and $T_{11}(p)$ given there is covered by the experiments described below.

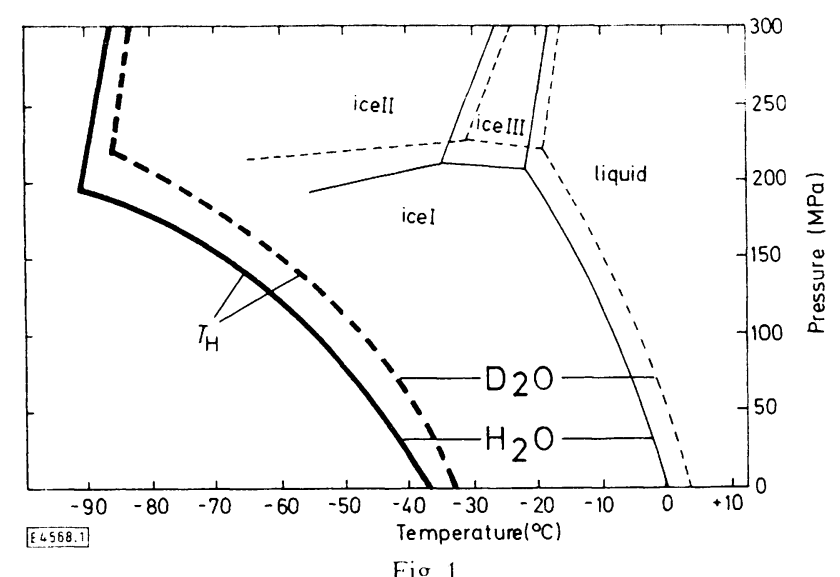

Fig. 1

Part of the phase diagrams of $\mathrm{H}_{2} \mathrm{O}$ and $\mathrm{D}_{2} \mathrm{O}$ showing the melting pressure curves and the pressure dependence of the homogeneous nucleation temperature $T_{11}$

In recent years a variety of physical properties of supercooled water has been studied at atmospheric pressure and these studies have revealed the unique properties of water in the metastable state [3]. Kanno and Angell [4] also succeeded in studying the compressibility of supercooled $\mathrm{H}_{2} \mathrm{O}$ and $\mathrm{D}_{2} \mathrm{O}$ to $T=243 \mathrm{~K}$ and pressures up to $p=190 \mathrm{MPa}$. The only experiments that have been extended at elevated pressures down to the respective homogeneous nucleation temperatures are to our knowledge the longitudinal proton relaxation time $\left(T_{1}\right)$ studies on emulsified $\mathrm{H}_{2} \mathrm{O}$ by the present authors [5]. In these studies it could be shown that the reorientational motions in supercooled water are slowed down by three to four orders of magnitude if water is supercooled from $270 \mathrm{~K}$ to $187 \mathrm{~K}$

Quantitative analysis of the proton relaxation data however is complicated, since the protons relax by dipole-dipole interaction and the relaxation rate observed is a sum of the intra- and intermolecular contributions.

These older studies are completed with the results presented here by deuterium $T_{1}$-measurements on emulsified heavy water. The deuterons of $\mathrm{D}_{2} \mathrm{O}$ relax by quadrupole relaxation and the experimental $T_{1}$ thus contains only an intramolecular contribution. In principle it should thus be feasible to separate from an analysis of the proton and deuteron relaxation rates the intra- and intermolecular contributions to the proton $T_{1}$. However, the strong isotope effect observed. when comparing light and heavy water renders such a procedure fairly inaccurate.

The water droplets in the emulsions studied here do have an average diameter of $5 \cdot 10^{-6} \mathrm{~m}$. It could thus be argued that in these small droplets surface effects change the behaviour of the whole aqueous phase [6]. However, previous $T_{1}$-results obtained by other authors $[7-10]$ in the range $T_{\mathrm{m}} \leq T \leq T_{\mathrm{m}}+30 \mathrm{~K}$ in the bulk liquid and in emulsions as well as our own data given below do not show any systematic deviation in this region of overlap, thus proving. that the emulsification does not influence the physical properties under study.

\section{Experimental}

The spin-lattice relaxation times of the deuterons were obtained at $15.4 \mathrm{MHz}$ on a Varian XL-100-15 FT-NMR spectrometer equipped with a high power pulse amplifier and interfaced to a $16 \mathrm{~K}-\mathrm{V}$ arian 620-100 computer by a $\frac{\pi}{3}-T-\pi-\tau-\frac{\pi}{2}$ pulse sequence. The emulsions were contained in a high pressure glass capillary with i.d. $1.2 \mathrm{~mm}$ and o.d. $7 \mathrm{~mm}$. Details of the high pressure equipment have been described elsewhere [11.12]. The pressure range covered extends to $300 \mathrm{MPa}$. The applied pressure was measured by a precision Bourdon gauge (Heise. Newton. CT. USA) to $\pm 0.5 \mathrm{MPa}$ and was generated with standard $\frac{1}{8}$ equipment (HIP. Erie. PA. USA). The temperatures were determined to $\pm 0.5 \mathrm{~K}$ by a chromel-alumel thermocouple. The emulsions were obtained following a procedure suggested by Rasmussen and McKenzie [1]. They were prepared from triply distilled heavy water $(99.75 \%$, E. Merck. Darmstadt. BRD) emulgated in a mixture of $50 \% \mathrm{w} / \mathrm{w}$ methylcyclohexane and $50 \% \mathrm{w} w$ methylcyclopentane (E. Merck. Darmstadt. BRD). In order to stabilize the emulsions $4 \% \mathrm{w} / \mathrm{w}$ of an emulgator (Span 65 , Sorbitantristearat. Serva. Heidel berg. BRD) was added to the cycloalkanes. The components were degassed carefully on a high vacuum line by at least five freezepump-thaw cycles to a final pressure of $7 \mathrm{mPa}$. The emulsions were prepared by rigorously slashing the mixture through a stainless steel net $(635$ mesh. Spörl \& Co. Sigmaringendorf. BRD) in a sealed glass tube. The $\tau_{0}$-data were computer fitted with a standard nonlinear least squares fit program.

\section{Theoretical}

Under the conditions prevailing in our experiments the deuteron spin relaxation is dominated by its intramolecular quadrupole interaction. The time-dependence of this interaction is due to the rotational motion of the water molecules. There is no evidence for any contribution from either chemical exchange of the deuterons or from dipolar interactions. The measured spin-lattice relaxation rate $1 T_{1}$ of the deuterium nucleus is given in the theory of nucleat magnetic relaxation $[13-15]$. assuming that the electric field gradient tensor has cylindrical symmetry about the O-D bond $[16.17]$ by

$\frac{1}{T_{1}}=\frac{3}{80}\left(\frac{e^{2} q Q}{h}\right)^{2}: J\left(\omega_{0}\right)+4 J\left(2\left(\omega_{0}\right)\right)^{2}$

$\left(e^{2} q Q\right) / \hbar$ is the deuteron quadrupole coupling constant. The spectral density functions are given by

$J\left(\alpha()_{0}\right)=\int_{-i}^{1} G_{2}(\tau) \exp \left(i \alpha()_{0} \tau\right) \mathrm{d} \tau$

where $G_{2}(\tau)$ is the normalized correlation function of the elements of the Wigner rotation matrix of rank two [14.15] describing the time-dependent orientation of the electric field-gradient tensor relative to the laboratory coordinate system defined by the direction of the static magnetic field. We will assume, that the motion of the molecule is isotropic and can be described by a Markov process characterized by a single correlation time $\tau_{\theta}$. Under these assumptions, $T_{1}$ is given by

$\frac{1}{T_{1}}=\frac{3}{40}\left(\frac{e^{2} q Q}{\hbar}\right)^{2}\left\{\frac{\tau_{\theta}}{1+\omega_{0}^{2} \tau_{\theta}^{2}}+\frac{4 \tau_{\theta}}{1+4 \omega_{0}^{2} \tau_{\theta}^{2}}\right\}$

which in the extreme narrowing limit $\left(\omega \omega_{0}^{2} \tau_{0}^{2} \ll 1\right)$ reduces to

$\frac{1}{T_{1}}=\frac{3}{8}\left(\frac{e^{2} q Q}{\hbar}\right)^{2} \cdot \tau_{\theta}$.

\section{Results}

Fig. 2 contains the spin-lattice relaxation times of the deuterons between $283 \mathrm{~K}$ and $188 \mathrm{~K}$ and pressures up to $300 \mathrm{MPa}$. The data are also compiled in Table 1. 


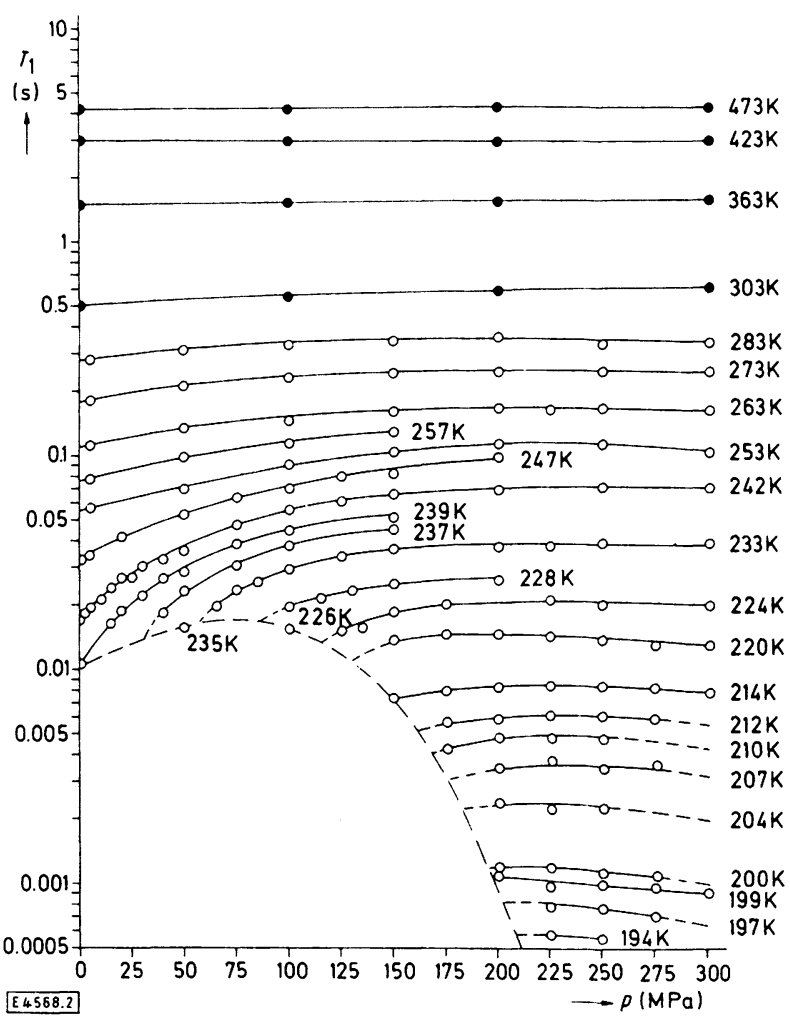

Comparison of our $T_{1}$-data. obtained in emulsions. with the longitudinal relaxation times $T_{1}$ by Jonas et al. [8] and DeFrics et al. [9] measured in bulk liquid heavy water are within experimental error the same. corroborating the assumption that emulsification does not change the properties of the liquid water. The same holds for the atmospheric pressure results obtained in bulk and emulsified $\mathrm{D}_{2} \mathrm{O}$ by Hindman et al. $[18.19]$ and our results.

Inspection of Fig. 2 shows, as has already been demonstrated [5]. that the spin-lattice relaxation times in liquid water at low temperatures and low pressures behave rather anomalous compared with more normal substances like liquid $\mathrm{ND}_{3}[20]$ and $\mathrm{D}_{2} \mathrm{~S}[21]$. The deuteron $T_{1}$ s increase with raising pressure. the increase being steepest at the lowest temperatures. This anomaly is considerably more pronounced in liquid $\mathrm{D}_{2} \mathrm{O}$ as compared with liquid $\mathrm{H}_{2} \mathrm{O}$ in the same temperature and pressure range. This is seen most clearly in the $239 \mathrm{~K}$ isotherm in $\mathrm{D}_{2} \mathrm{O}$, where $T_{1}$ increases by a factor -5 . whereas in the $237 \mathrm{~K}$ isotherm of $\mathrm{H}_{2} \mathrm{O}$ the increase amounts only to a factor of 2.4 in the pressure range $0-150 \mathrm{MPa}$. In the low temperature $(T \leq 207 \mathrm{~K})$ and high pressure $(p \geq 200 \mathrm{MPa})$ region however, water behaves like a normal viscous liquid with $T_{1}$ slightly decreasing with increasing pressure. Fig. 3 compares the $225 \mathrm{MPa}$ isobars of $\mathrm{D}_{2} \mathrm{O}$ and $\mathrm{H}_{2} \mathrm{O}[5]$. The minimum in the $T_{1}$-isobar. already found in $\mathrm{H}_{2} \mathrm{O}$, could also be detected in the case of $\mathrm{D}_{2} \mathrm{O}$.

Fig. 2

Pressure and temperature dependence of the longitudinal relaxation times $T_{1}$ of the deuterons in $\mathrm{D}_{2} \mathrm{O}$. Own results: open circles. Jonas et al. $[7-10]$ : full circles

Table 1

Experimental longitudinal relaxation times $T_{1}(\mathrm{~ms})$ of the deuterons in $\mathrm{D}_{2} \mathrm{O}$

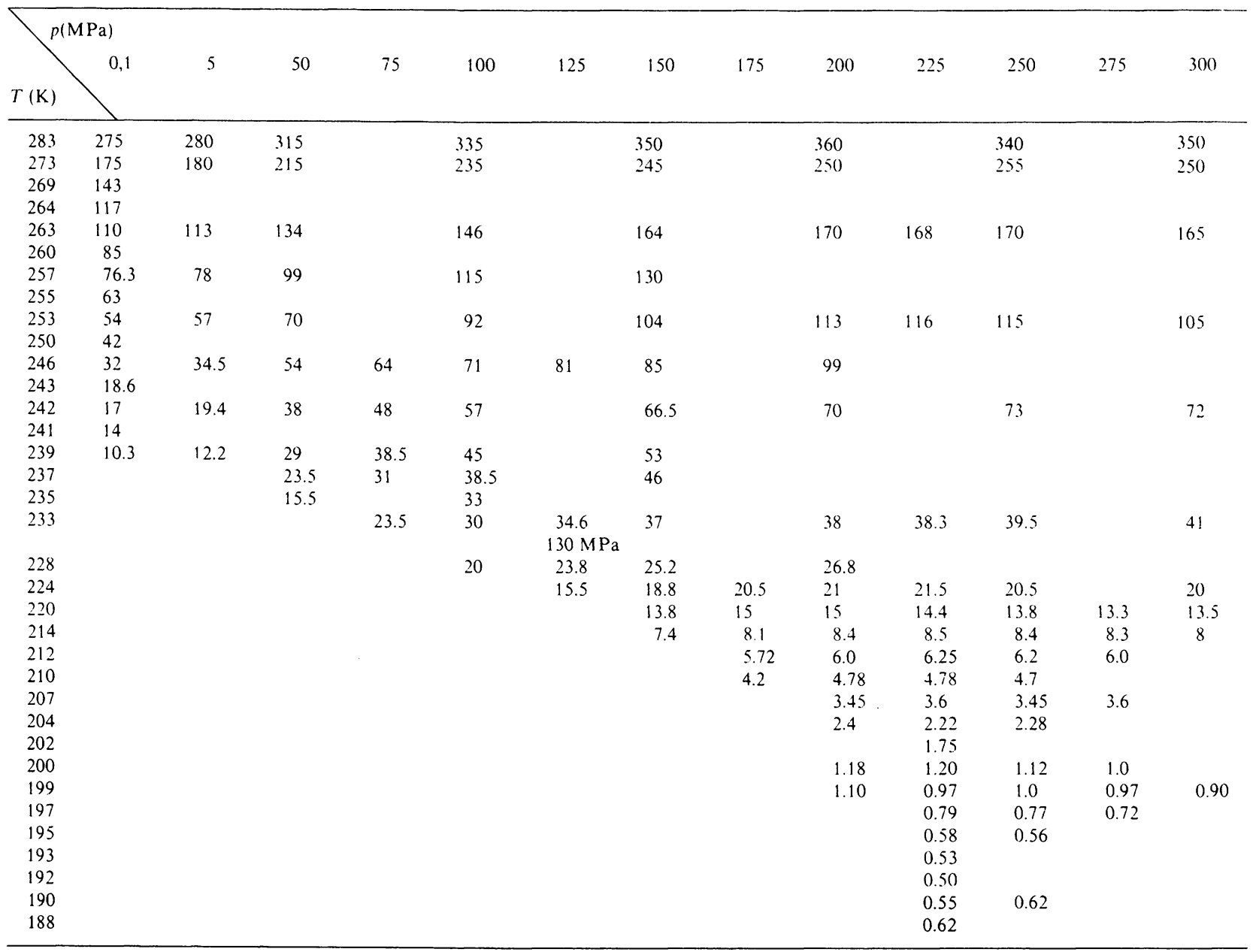




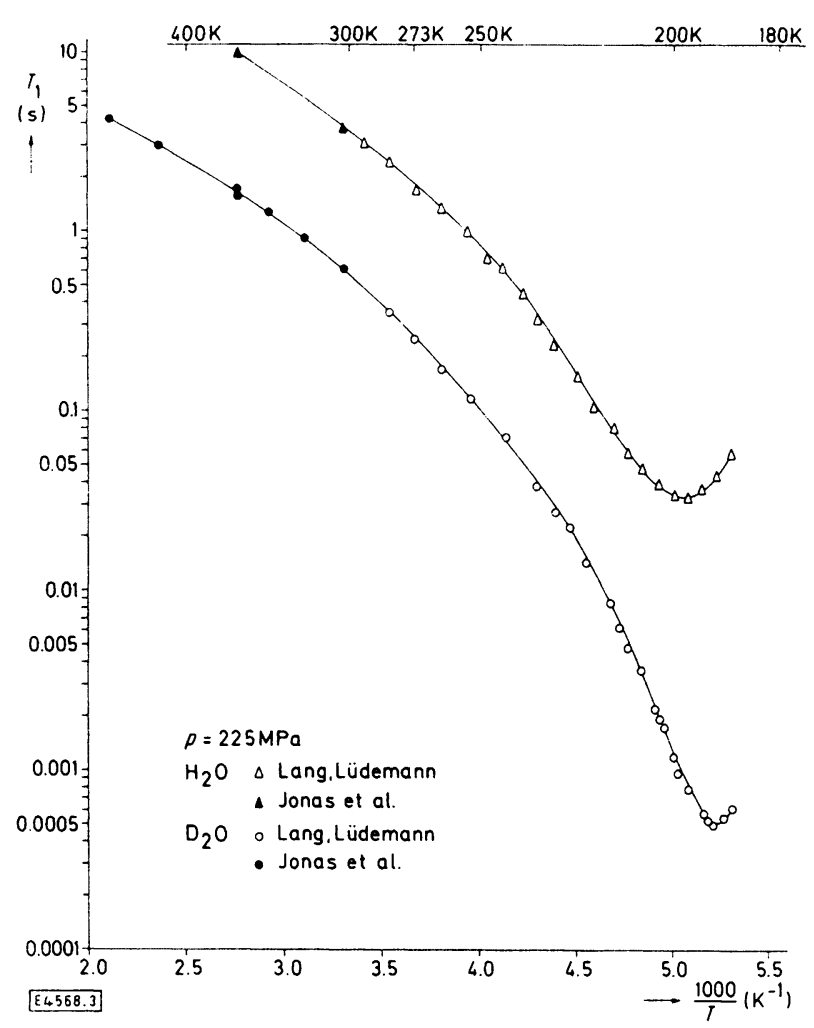

Fig. 3

$225 \mathrm{MPa}$ isobar of the longitudinal relaxation times $T_{1}$ of the deuterons in $\mathrm{D}_{2} \mathrm{O}$. For comparison the proton $T_{1}$ of $\mathrm{H}_{2} \mathrm{O}[5]$ are included
The temperature of the minimum in $\mathrm{D}_{2} \mathrm{O}$ is shifted by $5 \mathrm{~K}$ to lower temperatures $\left(T_{\min }=192 \mathrm{~K}\right)$ as compared to $\mathrm{H}_{2} \mathrm{O}\left(T_{\min }=197 \mathrm{~K}\right)$. Most unfortunately the increase of the deuterium $T_{1}$ beyond the minimum can only be measured in a short temperature interval. since it occurs in close proximity of the homogeneous nucleation temperature.

\section{Discussion}

1) Estimate of the Deuterium Quadrupole Coupling Constant $\left(C_{\mathrm{DQC}}\right)$

Theory predicts a minimum in Eq. (1) if $\left(0_{0} \tau_{B}=0.6158\right.$ $[13,22]$. This minimum in the $225 \mathrm{MPa} T_{1}$-isobar can be seen in Fig. 3. Because there is no parameter left in Eq. (1) we can calculate an experimental value of the $C_{\mathrm{DQC}}$ without any further assumption. With $T_{1}=0.5 \pm 0.06 \mathrm{msec}$ at $T=192 \mathrm{~K}$ we get

$\frac{e^{2} q Q}{h}=214 \pm 12 \mathrm{kHz}$

Several measured or estimated $C_{\mathrm{DQC}}$ 's from the literature are collected for comparison in Table 2 . The value obtained for the $C_{\mathrm{DQC}}$ is essentially the same as in the case of ice $I h .[23,24]$. This shows that the short range order in water at low temperatures must be very close to that of the crystal. As will be discussed later in this paper, the major influence of pressure is to bend the hydrogen bond angles, but changes of this angle do influence the $C_{\mathrm{DQC}}$ only very weakly [26]. Consequently this quantity should vary only a little in the moderate pressure range covered by our experiments.

Table 2

Comparison of the deuteron quadrupole coupling constant derived from the minimum of the $T_{1}(T)$-curve with data collected from the literature

\begin{tabular}{|c|c|c|c|c|}
\hline $\mathrm{D}_{2} \mathrm{O}$ & $\frac{e^{2} q Q}{h}(\mathrm{kHz})$ & $\eta$ & Ref. & \\
\hline Ice Ih & $\begin{array}{l}213.4 \pm 0.3 \\
213.2 \pm 0.8\end{array}$ & $\begin{array}{l}0.112 \pm 0.005 \\
0.1 \pm 0.002\end{array}$ & $\begin{array}{l}23 \\
24\end{array}$ & $\begin{array}{l}\text { polycrystalline, } T=77 \mathrm{~K} \\
\text { single crystal, } T=263 \mathrm{~K}\end{array}$ \\
\hline Ice II & $\begin{array}{l}225.8 \pm 0.3 \\
219.8 \pm 0.3 \\
226.1 \pm 0.3 \\
220.3 \pm 0.3\end{array}$ & $\begin{array}{l}0.127 \pm 0.005 \\
0.134 \pm 0.005 \\
0.1 \pm 0.005 \\
0.102 \pm 0.005\end{array}$ & 25 & polycrystalline, $T=77 \mathrm{~K}$ \\
\hline Ice IX & $220 \pm 3$ & $0.12 \pm 0.03$ & 26 & polycrystalline, $T=77 \mathrm{~K}$ \\
\hline Vapour & $318.6 \pm 2.4$ & $0.06 \pm 0.16$ & 27 & HDO \\
\hline supercooled liquid & $214 \pm 12$ & & $\begin{array}{l}\text { this } \\
\text { work }\end{array}$ & $\begin{array}{l}T=192 \mathrm{~K}, p=225 \mathrm{MPa} \text { minimum condition of } T_{1}(T) \text { curve } \\
\text { isotropic reorientation }\end{array}$ \\
\hline Liquid & $230 \pm 10$ & & 28 & $\tau_{\theta}\left({ }^{1} H\right)=\tau_{\theta}\left({ }^{2} H\right)$ \\
\hline Liquid & $\begin{array}{l}208 \\
250\end{array}$ & & 29 & $\begin{array}{l}\tau_{\theta}\left({ }^{2} \mathrm{H}\right)=\frac{1}{3} \tau_{\mathrm{dicl}} \\
\tau_{\mathrm{dicl}} \text { with inner field correction }\end{array}$ \\
\hline Liquid & 258.6 & & 18 & $\tau_{\theta}\left({ }^{2} \mathrm{H}\right)=\frac{1}{3} \tau_{\text {diel }}$, with inner field correction, $C_{\mathrm{DQC}}=$ const. \\
\hline Liquid & 230 & & $\begin{array}{l}9 \\
8\end{array}$ & $\begin{array}{l}\text { Debye-equation, } C_{\mathrm{DQC}}(\neq f(T))=\text { const. } \\
\sim 5 \% \text { variation of } C_{\mathrm{DQC}} \text { with density }\end{array}$ \\
\hline Liquid & $226-203$ & & 7 & $\sim 10 \%$ decrease of $C_{\mathrm{DQC}}$ with increasing density, $C_{\mathrm{DQC}}=$ const. \\
\hline Liquid & 222 & & 30 & $\tau_{\theta}\left({ }^{2} \mathrm{H}\right) \simeq 1.23 \cdot \tau_{\theta}\left({ }^{1} \mathrm{H}\right)$ \\
\hline $\begin{array}{l}\mathrm{LiCl}-\mathrm{D}_{2} \mathrm{O} \\
\quad \text { aqueous solution }\end{array}$ & $230 \pm 10$ & & 31 & fit to Cole-Davidson distribution for $\tau_{\theta}$ \\
\hline $\begin{array}{l}\mathrm{LiCl}-\mathrm{D}_{2} \mathrm{O} \\
\quad 11 \mathrm{M} \text { aqueous solution }\end{array}$ & 150 & & 32 & minimum condition of $T_{1}(T)$-curve anisotropic reorientation \\
\hline $\begin{array}{l}\mathrm{THF} / \mathrm{D}_{2} \mathrm{O} \\
\quad \text { clathrat hydrate }\end{array}$ & $215 \pm 2$ & $0.11 \pm 0.01$ & 33 & $T=37 \mathrm{~K}$ \\
\hline $\begin{array}{l}\text { p-dioxane } / \mathrm{D}_{2} \mathrm{O} \\
\text { clathrat hydrate }\end{array}$ & 217 & 0.1 & 34 & $T=63 \mathrm{~K}$ \\
\hline
\end{tabular}


One further comment should be made to the result obtained by Powles et al. [28]. They assumed in their analysis that the reorientational correlation times in $\mathrm{H}_{2} \mathrm{O}$ and $\mathrm{D}_{2} \mathrm{O}$ are the same, i. e. $\tau_{\theta}\left({ }^{1} \mathrm{H}\right)=\tau_{\theta}\left({ }^{2} \mathrm{H}\right)$. However, our preliminary ${ }^{17} \mathrm{O}-T_{1}$ measurements in $\mathrm{H}_{2}{ }^{17} \mathrm{O}$ and $\mathrm{D}_{2}{ }^{17} \mathrm{O}$ in the temperature range $243 \mathrm{~K}$ to $383 \mathrm{~K}$ and pressures up to $300 \mathrm{MPa}$ show that they should transform according to the corresponding moments of inertia, i. e. the ratio of the measured ${ }^{17} \mathrm{O}$ spin-lattice relaxation times is

$\frac{T_{1}\left(\mathrm{H}_{2}{ }^{17} \mathrm{O}\right)}{T_{1}\left(\mathrm{D}_{2}{ }^{17} \mathrm{O}\right)} \approx 1.3$ compared to $\left(\frac{\left\langle I_{\mathrm{D}_{2} \mathrm{O}}\right\rangle}{\left\langle I_{\mathrm{H}_{2} \mathrm{O}}\right\rangle}\right)^{12}=1.38$.

With $\tau_{\theta}\left({ }^{2} \mathrm{H}\right)=1.3 \cdot \tau_{\theta}\left({ }^{1} \mathrm{H}\right)$ their estimated value of the $C_{\mathrm{DQC}}$ should lower to $204 \mathrm{kHz}$ which is close to our value. Different authors have claimed the $C_{\mathrm{DQC}}$ to be independent of temperature $[9,18]$ and only slightly decreasing with increasing density $[8,9,35,36]$. We therefore assume a constant value of the $C_{\mathrm{DQC}}$ over the range of temperatures and pressures measured. However, with increasing temperature the $\mathrm{O}-\mathrm{D} \ldots \mathrm{O}$ distance will become larger $[27,38]$, and this widening of the average $\mathrm{R}_{\mathrm{OO}}$-distance must have an effect upon the $C_{\mathrm{DQC}}[16,17,39,40]$. It is trivial to predict qualitatively from an inspection of the results collected in Table 2 that raising the temperature should lead to an increase of the $C_{\mathrm{DQC}}$. However, it is at present impossible to make any reliable quantitative estimate of this change. In the following we will therefore calculate all correlation times with the $C_{\mathrm{DOC}}$ derived from the $T_{1}$-minimum condition.

\section{2) Comparison of the $T_{1}$-Minimum in the High Pressure Isobars of $\mathrm{H}_{2} \mathrm{O}$ and $\mathrm{D}_{2} \mathrm{O}$}

Comparing the depth of the respective minima in the $\mathrm{H}_{2} \mathrm{O}$ and $\mathrm{D}_{2} \mathrm{O}$ isobars offers the possibility to test the assumption underlying the interpretation of the $\mathrm{H}_{2} \mathrm{O}$-data in the region of the minimum of the $T_{1}$ isobar [5]. One gets for the ratio of the measured spin-lattice relaxation rates of the protons and deuterons at the corresponding minima of the $225 \mathrm{MPa}$ isobars

$\left(\frac{1}{T_{1}}\right)_{\mathrm{exp}}^{\mathrm{H}_{2} \mathrm{O}} /\left(\frac{1}{T_{1}}\right)_{\exp }^{\mathrm{D}_{2} \mathrm{O}}=1.56 \cdot 10^{-2}$.

With $r_{\mathrm{HH}}=1.56 \AA$ and $C_{\mathrm{DQC}}=214 \mathrm{kHz}$ theory predicts for the ratio of the intramolecular relaxation rate of $\mathrm{H}_{2} \mathrm{O}$ and the measured (i. e. completely intramolecular) relaxation rate of $\mathrm{D}_{2} \mathrm{O}$ at the minimum $\left(\omega_{0} \tau_{\theta} \simeq 0.6158\right)$

$\left(\frac{1}{T_{1}}\right)_{\text {intra }}^{\mathrm{H}_{2} \mathrm{O}} /\left(\frac{1}{T_{1}}\right)_{\exp }^{\mathrm{D}_{2} \mathrm{O}}=1.35 \cdot 10^{-2}$.

Therefore, at the minimum of the proton $T_{1}$ isobar $(p=$ $225 \mathrm{MPa}$ ) the intermolecular relaxation rate $\left(\frac{1}{T_{1}}\right)_{\text {inter }}^{\mathrm{H}_{2} \mathrm{O}}$ amounts only to about $14 \%$, which in view of a $10 \%$ error in $T_{1}$ justifies the assumption, previously made, that almost all of the measured relaxation rate is due to intramolecular dipoledipole interactions.

\section{3) Temperature and Pressure Dependence of the Reorientational} Correlation Times

Rotational correlation times were calculated with Eq. (2) and below $210 \mathrm{~K}$ with Eq. (1) and the $C_{\mathrm{DQC}}$ of $214 \mathrm{kHz}$ derived above. Their pressure dependence reflects that of the relaxation times and in the low temperature, low pressure region shows clearly the anomalous increase in rotational mobility with raising pressure. It has been suggested. that the influence of pressure is a distortion of the hydrogen bond direction in the random hydrogen bonded network of liquid water with an accompanying weakening of the respective interaction [41]. The lower the temperature. the stronger this distortional effect of the applied pressure seems to be. This is consistent with the view that strong supercooling leads to an increased straightening of $\mathrm{O}-\mathrm{H} \ldots \mathrm{O}$-bonds in the random hydrogen bonded network and that the major effect of pressure in the low pressure region is to deform hydrogen bond angles $[42,43]$. This tendency is not found at higher pressures. where water behaves like a normal viscous liquid. i. e. the molecular mobility decreases slightly with raising pressure [20]. Similar effects have been found in the case of the self diffusion coefficient $D$, where diffusivity increases with

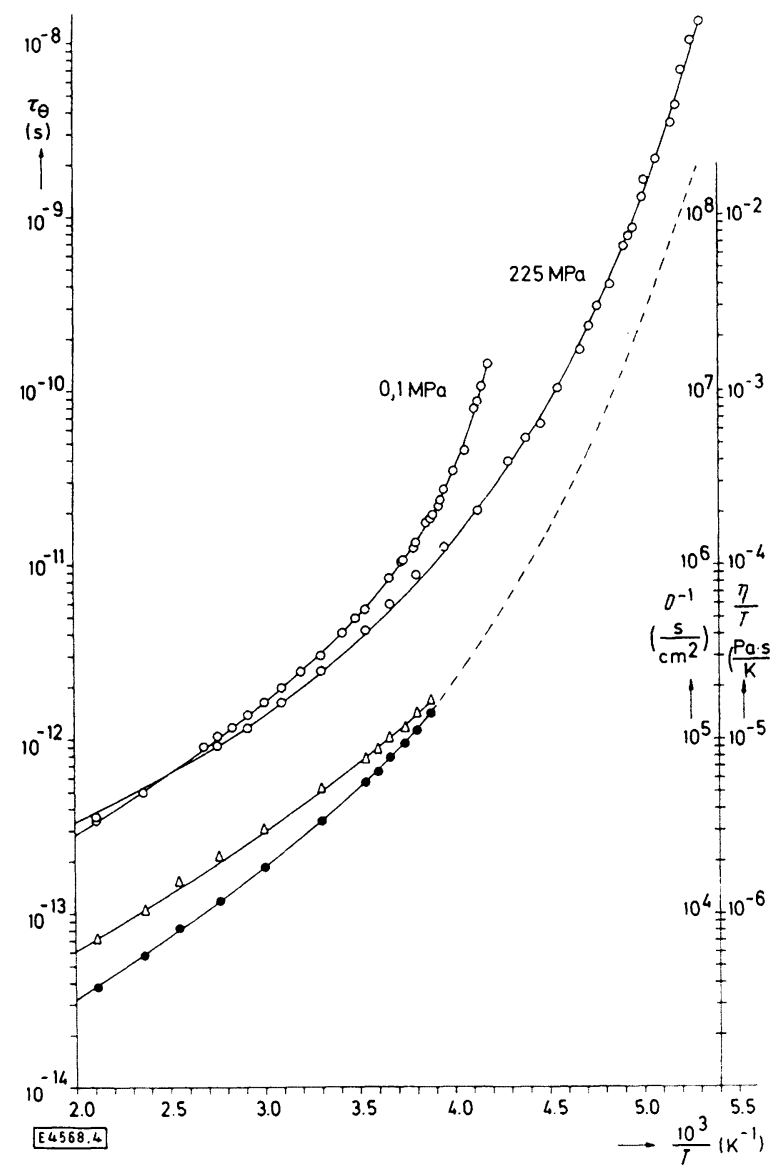

Fig. 4

$0.1 \mathrm{MPa}$ and $225 \mathrm{MPa}$ isobars of the reorientational correlation times $\tau_{\theta}$ (open circles). For comparison the $225 \mathrm{MPa}$ isobars of $D^{-1}$ (open triangles, $D=$ selfdiffusion coefficient) and $\eta T$ (full circles. $\eta=$ viscosity) obtained by Jonas et al. [8,9] in the stability region of $\mathrm{D}_{2} \mathrm{O}$ are included, together with an extrapolation of $\eta T$ to the homogeneous nucleation temperature $T_{11}$ 
increasing pressure as a consequence of the removal of a dominant slow component $[44]$ and with the specific heat $C_{p}$ at constant pressure which becomes insensitive to pressure at higher pressures $(p \geq 200 \mathrm{MPa})[45]$.

At the higher pressures the temperature dependence of the reorientational correlation time is given by the VTF-equation

$\tau_{\theta}=\tau_{0} \cdot \exp \left(\frac{B}{T-T_{0}}\right)$

which often describes the behaviour of viscous liquids [46. 47]. Water at pressures $p \geq 200 \mathrm{MPa}$ therefore returns to normal supercooled liquid behaviour. The temperature $T_{0}$ corresponds to an internal equilibrium low temperature limit of the liquid $[47-50] . T_{0}$ has, however. never been measured directly in the case of water because of fast crystallization occurring at the homogeneous nucleation temperature $T_{\mathrm{H}}$. We have least squares fitted our $\tau_{\theta}$-data over the whole range of temperatures measured, together with data from the Refs. [7-9. $18.19]$ so that in the most favorable case $(p=225 \mathrm{MPa})$ a temperature range extending from $473 \mathrm{~K}$ down to $188 \mathrm{~K}$ could be included. The best fit value for the ideal glass transition temperature was $T_{0}=141 \pm 2 \mathrm{~K}$ in the pressure range $p=200 \mathrm{MPa}-300 \mathrm{MPa}$. At pressures below $p=200 \mathrm{MPa}$ the parameter $T_{0}$ increases with decreasing pressure. Especially at saturation pressure the fit was much worse compared to the higher pressures. The parameter obtained by fitting $\tau_{\theta}$

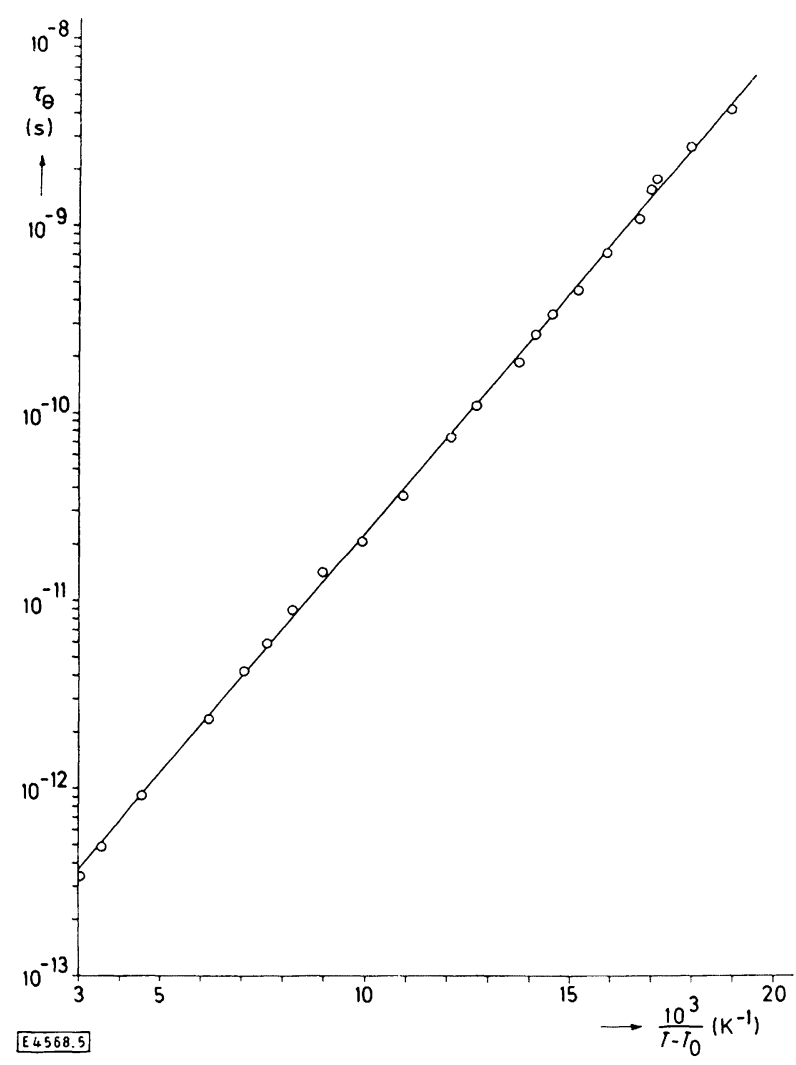

Fig. 5

Representation of the $300 \mathrm{MPa}$ isobar of the reorientational correlation times $\tau_{\theta}$ by the VTF-equation (Eq. (4)). Solid line is obtained from a least-squares fit of the data $\left(T_{0}=140 \mathrm{~K}\right.$. $\left.B=591.3 \mathrm{~K} \cdot \tau_{0}=6.26 \cdot 10^{-1+} \mathrm{s}\right)$ over the whole pressure range measured and temperatures from $473 \mathrm{~K}$ down to the respective homogeneous nucleation temperatures are collected in Table 3. The temperature dependence of $\tau_{0}$ at $p=225 \mathrm{MPa}$ and $300 \mathrm{MPa}$ is plotted against $1 /\left(T-T_{0}(p)\right)$ in Figs. 5 and 6 . The full line represents

Table 3

Parameters of the VTF-equation (Eq. (4)) obtained from the leastsquares fits of the $\tau_{\theta}$-isobars (temperature range $473 \mathrm{~K} \geq T \geq T_{\mathrm{H}}$ )

\begin{tabular}{cccc}
\hline$p(\mathrm{MPa})$ & $T_{0}(\mathrm{~K})$ & $B(\mathrm{~K})$ & $\tau_{0}(\mathrm{~s})$ \\
\hline 0.1 & 185 & 373.1 & $1.20 \cdot 10^{-13}$ \\
50 & 165 & 481.5 & $7.90 \cdot 10^{-14}$ \\
100 & 140 & 640.0 & $5.22 \cdot 10^{-14}$ \\
150 & 133 & 672.5 & $4.90 \cdot 10^{-14}$ \\
200 & 139 & 604.0 & $6.07 \cdot 10^{-14}$ \\
225 & 141 & 582.3 & $6.61 \cdot 10^{-14}$ \\
250 & 142 & 563.3 & $7.03 \cdot 10^{-14}$ \\
300 & 140 & 591.3 & $6.26 \cdot 10^{-14}$ \\
\hline
\end{tabular}

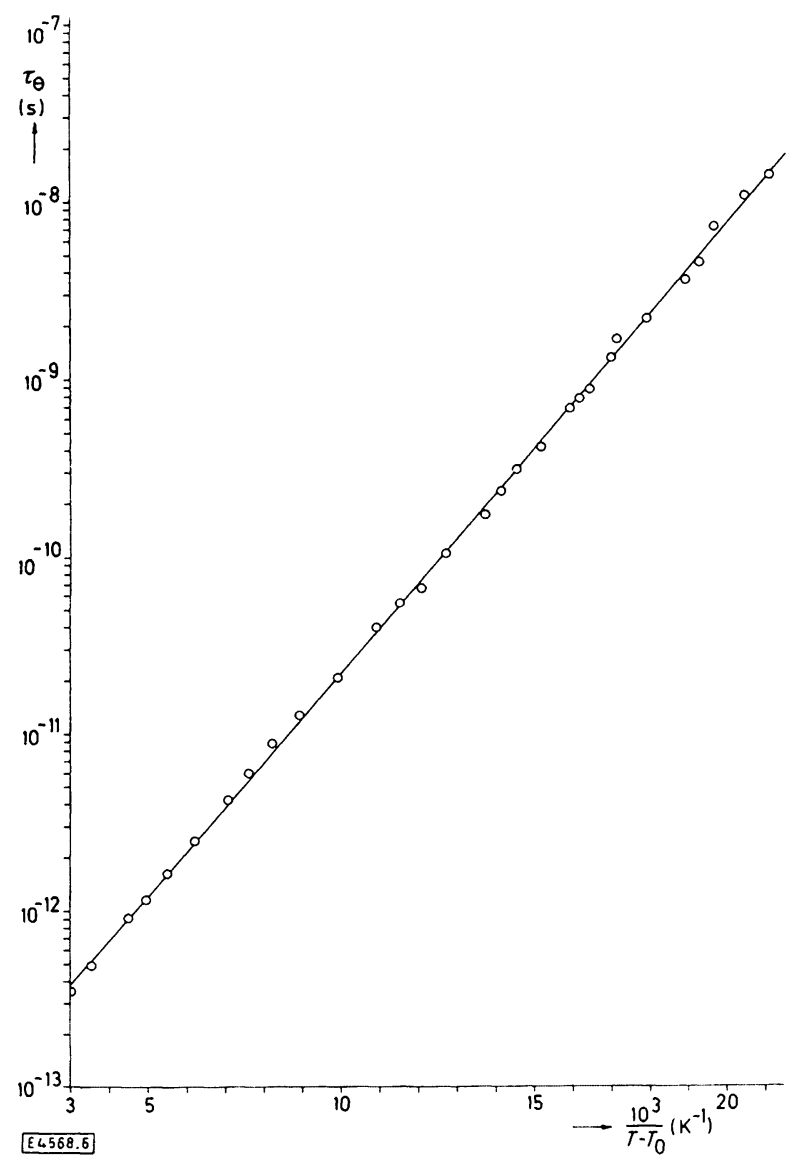

Fig. 6

Representation of the $225 \mathrm{MPa}$ isobar of the reorientational correlation times $\tau_{\theta}$ by the VTF-equation (Eq. (4)). Solid line is obtained from a least-squares fit of the data $\left(T_{0}=141 \mathrm{~K} . B=582.3 \mathrm{~K}\right.$. $\tau_{0}=6.61 \cdot 10^{-1+} \mathrm{s}$ )

the VTF-equation with the parameters given in Table 3 . The value of the glass transition temperature $T_{0}=141 \pm 2 \mathrm{~K}$ of high pressure heavy water is close to the experimental glass transition temperature $T_{\mathrm{g}}=140 \mathrm{~K}$ obtained with vapordeposited vitreous water $[45,51]$ and also to that extrapolated from binary aqueous solutions, $T_{\mathrm{g}}=138 \pm 2 \mathrm{~K}$ [47], but not with the $T_{0}=200 \mathrm{~K}$ estimated from an analysis of 
the $T$-dependence of the self diffusion coefficient [52]. The preexponential factor $\tau_{\theta}$ corresponds to a frequency of $i \approx 560 \mathrm{~cm}^{-1}$ which lies in the frequency range of the librational motions of $\mathrm{D}_{2} \mathrm{O}$ observed in the IR and Raman spectra of heavy water [53]. These motions therefore appear to reflect the fluctuations connected with the liquid-glass transition of water. The abnormal increase of the $T_{0}$ parameter indicates that $\tau_{\theta}$ increases in the low pressure region much faster than is predicted by the VTF-equation. This fast increase must be due to anomalous fluctuations with a much stronger temperature dependence. Thus in the low pressure region the temperature dependence of the data can only be accounted for by an equation recently proposed by Speedy and Angell [54]. which gives the variation of any dynamical variable with temperature as:

$\tau_{\theta}=\tau_{0}\left(\frac{T-T_{s}}{T_{s}}\right)^{-}$

The singular temperature $T_{N}(p)$ can. according to Angell [45] be interpreted as the boundary of the free energy surface for liquid water or as a line of metastable higher order transitions running across the free energy surface. We have least squares fitted all our $\tau_{\theta}$-data also with this equation. At pressures up to $100 \mathrm{MPa}$ the fit was excellent. including $\tau_{\theta}$-values at constant pressure from $473 \mathrm{~K}$ down to the homogeneous nucleation temperature $T_{11}(p)$. In Figs. 7 and $8 \tau_{f}$ versus $(T-T) / T_{s}$ is plotted. The full line represents the best fit to Eq. (5). The best fit parameter to Eq. (5) are collected in Table 4. The $150 \mathrm{MPa}$ isobar could be fitted with either Eqs. (4) or (5) with equal accuracy. whereas at higher pressures systematic deviations occurred in the fit of the data 10 Eq. (5). It can thus be concluded that the singular temperature $T_{s}$ decreases much faster with increasing pressure than does the homogeneous nucleation temperature and that at pressures between $150 \mathrm{MPa}$ and $200 \mathrm{MPa}$ it falls below the glass transition temperature $T_{0}$. This indicatis that the anomalous fluctuations

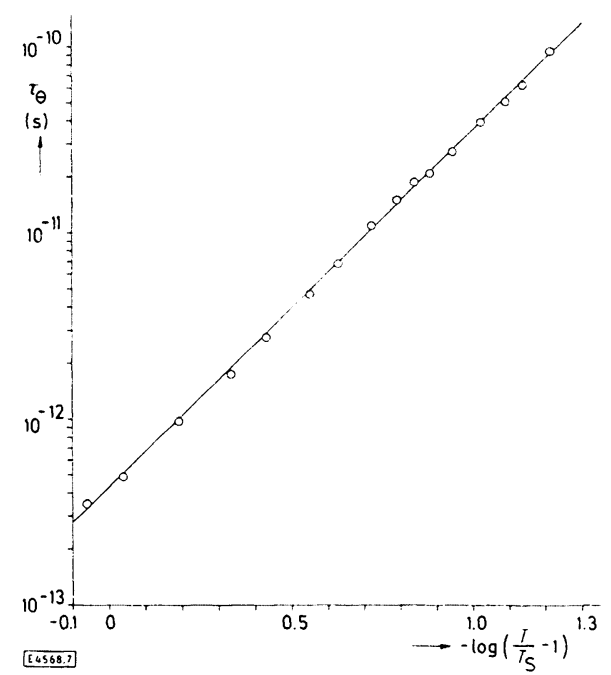

Fig. 7

Representation of the $50 \mathrm{MPa}$ isobar of the reorientational correlation times $\tau_{\theta}$ by Eq. (5). Solid line results from the least-squares fit of the $\tau_{\theta}$-data $\left(T_{S}=221 \mathrm{~K} . \because=1.925, \tau_{0}=4.23 \cdot 10^{-13} \mathrm{~s}\right)$

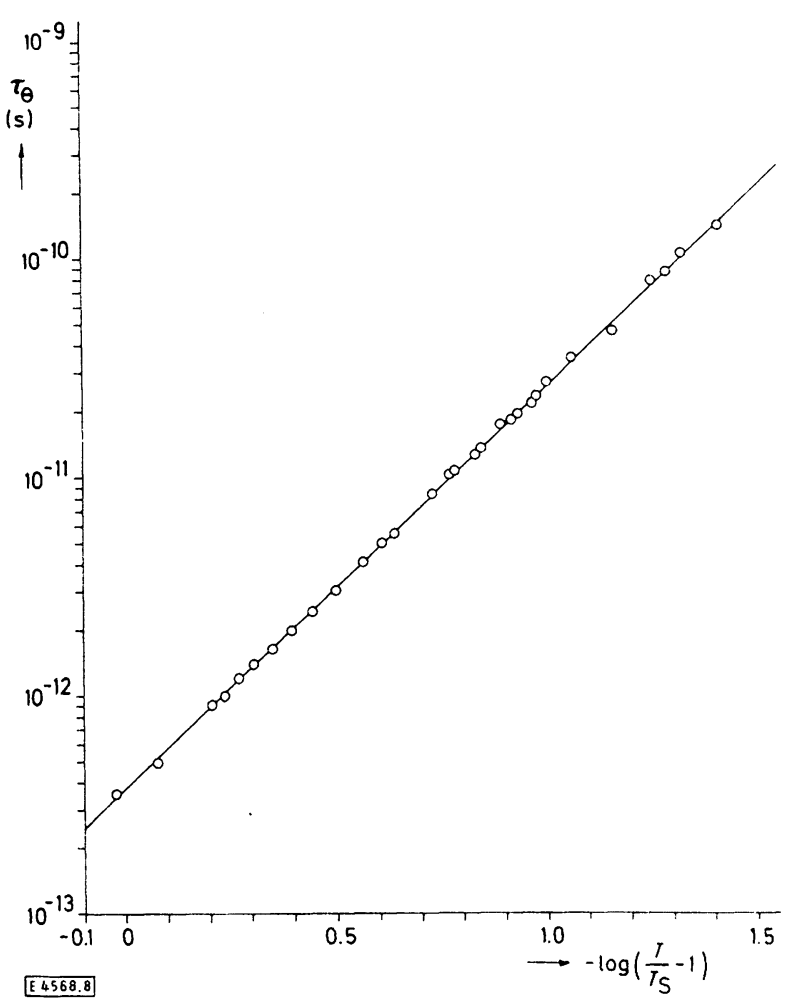

Fig. 8

Representation of the $0.1 \mathrm{MPa}$ isobar of the reorientational correlation times $\tau_{\theta}$ by Eq. (5). Solid line results from the least-squares fit of the $\tau_{\theta}$-data $\left(T_{s}=230 \mathrm{~K} . \gamma=1.848 . \tau_{0}=3.74 \cdot 10^{-13} \mathrm{~s}\right)$

Table 4

Parameters of Eq. (5) obtained from the least-squares fits of the $\tau_{0}$-isohars (temperature range $47.3 \mathrm{~K} \geq T \geq T_{H}$ )

\begin{tabular}{cccc}
\hline$p(\mathrm{MPa})$ & $T(\mathrm{~K})$ & $\because$ & $\tau_{0}(\mathrm{~s})$ \\
\hline 0.1 & 230 & 1.848 & $3.74 \cdot 10^{-13}$ \\
50 & 221 & 1.925 & $4.23 \cdot 10^{-13}$ \\
100 & 207 & 2.172 & $5.51 \cdot 10^{-13}$ \\
150 & 197 & 2.373 & $6.73 \cdot 10^{13}$ \\
\hline
\end{tabular}

inferred by the use of Eq. (5) are strongly suppressed with raising pressure so that at higher pressures $(p \geq 200 \mathrm{MPa}$ ) the dynamics of liquid water are governed by the fluctuations connected with the liquid-glass transition. The factor $\tau_{0}$ in Eq. (5) corresponds to a frequency $\hat{r} \simeq 60 \mathrm{~cm}^{-1}$ which is in the region of the hydrogen bond bending motions [537. Evidently the anomalous fluctuations grow and decay with a greater time constant and can only develop in the open hydrogen bonded network known to exist at low temperatures and low pressures in water. As the nature of the open hydrogen bonded network changes with raising pressure to closer packed forms with strongly bent bonds. these anomalous fluctuations are suppressed by fluctuations dominating the dynamic behaviour of normal viscous liquids.

\section{4) Estimate of the Viscosity and the Self-Diffusion Coefficient of Water at $190 \mathrm{~K}$ and $225 \mathrm{MPa}$}

In Fig. 4 the $0.1 \mathrm{MPa}$ and $225 \mathrm{MPa}$ isobars of the correlation time $\tau_{\theta}$ are given together with the self-diffusion coefficient $D$ and the viscosity $\eta$ at $225 \mathrm{MPa}$ obtained by 
Jonas et al. $[8,9]$. It is common practice to use the latter two physical properties in combination with $\tau_{\theta}$ for the classification of the microdynamic behaviour of a liquid. However, there is little hope that either of the two transport coefficients can be measured for the low temperature. high pressure region of the supercooled water in the near future and the best one can do is to estimate $\eta$ and $D$ from the experimental $\tau_{\theta}$. If hydrodynamics can be applied. $\tau_{\theta}$ should be proportional to $1 / D$ and $\eta T$ [55]. As can be seen from an inspection of the data collected in Fig. 4 the temperature dependence of $1 / D$ and $\eta / T$ are not exactly parallel with each other nor parallels the $\tau_{\theta}$-isobar either of the two quantities. Considering the uncertainty about the correct $T$-dependence of the $C_{\mathrm{DQC}}$ the attempt to derive an extrapolation formula from the data given appears not justified. Assuming that the proportionality constant between $\tau_{\theta}$ and $1 / D$ or $\eta / T$ is independent of temperature between $258 \mathrm{~K}$ and $188 \mathrm{~K}$ we can however estimate the self-diffusion coefficients and the viscosities of supercooled water at the lowest temperatures of the metastable range to $\eta \simeq 4 \mathrm{~Pa} \cdot \mathrm{s}$ and $D \simeq 6 \cdot 10^{-9} \mathrm{~cm}^{2} / \mathrm{s}$. These figures indicate. that water does become a quite viscous liquid under these conditions. with a viscosity comparable to that of waterfree glycerol around room-temperature.

\section{Conclusions}

The small contribution of the intermolecular term to the dipole-dipole relaxation of supercooled water estimated from a comparison of the results obtained at the minimum of the $T_{1}$-isobars in $\mathrm{H}_{2} \mathrm{O}$ and $\mathrm{D}_{2} \mathrm{O}$ leads to the conclusion. that at the lowest temperatures the coordination around a central water molecule is essentially tetrahedral and that the local order of the supercooled liquid is best described by one of the low pressure phases of ice.

The increase of $T_{1}$ with pressure observed in the isotherms between $300 \mathrm{~K}$ and $240 \mathrm{~K}$ is much more pronounced for the deuterium relaxation data than for the proton results. This can only in part be explained by the compensatory effect of the intermolecular dipole-dipole relaxation contribution upon the proton $T_{1}$, which should become more efficient with increasing density. Preliminary measurements of the ${ }^{17} \mathrm{O}$ relaxation times, which can be described completely by quadrupole relaxation and thus monitor only intramolecular contributions, in light and heavy water [56] do reveal the same trend. The major source for this difference is in our opinion that the open hydrogen bonded network characteristic of supercooled water at low pressure is, at the lowest temperatures obtainable at $0.1 \mathrm{MPa}$. more perfectly developed in $\mathrm{D}_{2} \mathrm{O}$ than in $\mathrm{H}_{2} \mathrm{O}$. This conclusion is further corroborated by an inspection of the pressure dependence of the compressibility data obtained by Kanno and Angell [4] for supercooled $\mathrm{D}_{2} \mathrm{O}$ and $\mathrm{H}_{2} \mathrm{O}$. At $253 \mathrm{~K}$ for instance. the decrease in $\kappa_{T}$ with pressure is much more pronounced for $\mathrm{D}_{2} \mathrm{O}$ than for $\mathrm{H}_{2} \mathrm{O}$. The attempts to describe the temperature dependence of the correlation times do show that the supercooled water at pressures $p \leq 100 \mathrm{MPa}$ does reveral pronounced anomalies. $\tau_{\theta}$ does increase faster than described by the VTF-equation and the data presented here lend considerable support to the description of the temperature dependence by Eq. (5) proposed by Speedy and Angell [54].

At pressures $p \geq 200 \mathrm{MPa}$ water does behave like a normal supercooled liquid. The $\tau_{\theta}$-data are well represented by the VTF-equation and a reasonable glass temperature of $T_{0}=$ $141 \pm 2 \mathrm{~K}$. The unique properties of water appear thus to be confined to the low temperature and low pressure region, where an open hydrogen bonded network with $\mathrm{O}-\mathrm{D} \cdots \mathrm{O}$ angles close to $0 \mathrm{C}$ can develop.

The expert technical assistance by Mr. S. Heyn and Mr. R. Knott made this work feasible.

The least squares fitting of the data was done at the computer center of the University of Regensburg. Financial support by the $\mathrm{DFG}$ and the Fonds der Chemischen Industrie is gratefully acknowledged.

\section{References}

[1] D. H. Rassmussen and A. P. McKenzie, in: Water Structure and the Water-Polymer Interface. p. 126. ed. by H. H. Jellinek. Plenum. New York 1972.

[2] H. Kanno, R. J. Speedy. and C. A. Angell. Science 189. 880 (1975).

[3] C. A. Angell, Proc. IX ICPS 1979. U. Grigull, ed.. Pergamon Press, London, in press. "Supercooled and Superheated Water".

[4] H. Kanno and C. A. Angell. J. Chem. Phys. 7(), 4008 (1979).

[5] E. Lang and H.-D. Lüdemann. J. Chem. Phys. 67, 718 (1977).

[6] J. R. Hansen, J. Phys. Chem. 78,256 (1974).

[7] Y. Lee and J. Jonas, J. Chem. Phys. 57.4233 (1972).

[8] J. Jonas, T. DeFries, and D. J. Wilbur, J. Chem. Phys. 65, 582 (1976).

[9] T. DeFries and J. Jonas. J. Chem. Phys. 66. 5393 (1977).

[10] T. DeFries and J. Jonas, J. Chem. Phys. 66. 896 (1977).

[11] U. Gaarz and H.-D. Lüdemann. Ber. Bunsenges. Phys. Chem. 80.607 (1976).

[12] G. Völkel. E. Lang. and H.-D. Lüdemann. Ber. Bunsenges. Phys. Chem. 83, 722 (1979).

[13] A. Abragam, The Principles of Nuclear Magnetism. p. $313 \mathrm{ff}$. Oxford University Press. London 1961.

[14] H. W. Spiess, in: P. Diehl. E. Fluck. R. Kosfeld. eds., NMRBasic Principles and Progress. Vol. 15. p. $103 \mathrm{ff}$. SpringerVerlag, Berlin 1978.

[15] M. D. Zeidler, Ber. Bunsenges. Phys. Chem. 75. 229 (1971).

[16] S. D. Goren, J. Chem. Phys. 60, 1892 (1974).

[17] M. Weissmann. J. Chem. Phys. 44. 422 (1966).

[18] J. C. Hindman, A. J. Zielen, A. Svirmickas. and M. Wood. J. Chem. Phys. 54, 621 (1971).

[19] J. C. Hindman and A. Svirmickas. J. Phys. Chem. 77, 2487 (1973).

[20] H. Hauer, E. Lang, and H.-D. Lüdemann. Ber. Bunsenges. Phys. Chem. 83, 1262 (1979).

[21] H. Hauer, Diplomarbeit, Universität Regensburg 1978.

[22] T. M. Connor, Trans. Faraday Soc. 60. 1574 (1964).

[23] D. T. Edmonds and A. L. Mackay. J. Magn. Reson. 20, 515 (1975).

[24] P. Waldstein, S. W. Rabideau, and J. A. Jackson. J. Chem. Phys. 41, 3407 (1964).

[25] D. T. Edmonds, S. D. Goren. A. L. Mackay. and A. A. L. White, J. Magn. Reson. 23, 505 (1976).

[26] D. T. Edmonds, S. D. Goren. and A. A. L. White. J. Magn. Reson. 27, 35 (1977).

[27] P. Thaddeus; L. C. Krisher, and T. H. N. Loubser, J. Chem. Phys. 40, 257 (1964).

[28] J. G. Powles, M. Rhodes, and J. H. Strange. Mol. Phys. 11. $515(1966)$.

[29] D. W. Woessner, J. Chem. Phys. 40. 2341 (1964).

[30] H. G. Hertz and M. D. Zeidler. in: P. Schuster. G. Zundel. and C. Sandorfy, eds.. The Hydrogen Bond. Vol. 3. p. 1052. North-Holland Publ. Comp.. Amsterdam 1976. 
[31] N. Boden and M. Mortimer. J. Chem. Soc.. Faraday Trans. 2. $74,353(1978)$.

[32] J. F. Harmon and E. J. Sutter. J. Phys. Chem. 82.1938 (1978).

[33] D. W. Davidson. S. K. Garg. and J. A. Ripmeester, J. Magn. Reson. 31, 399 (1978).

[34] J. A. Ripmeester. Can. J. Chem. 55, 78 (1977)

[35] D. E. O'Reilly. Phys. Rev. A 7. 1659 (1973).

[36] D. E. O'Reilly, J. Phys. Chem. 78.1674 (1974).

[37] A. H. Narten. J. Chem. Phys. 55. 2263 (1971): 56.5681 (1972).

[38] A. H. Narten and H. A. Levy. in: Water - A Comprehensive Treatise, Vol. 1. p. $311 \mathrm{ff}$. ed. by F. Franks. Plenum Press, New York 1972.

[39] L. Mayas, M. Plato. C. J. Winscom. and K. Möbius. Mol. Phys. 36, 753 (1978).

[40] P. L. Olympia. Jr. and B. M. Fung. J. Chem. Phys. 5/. 2976 (1969).

[41] F. H. Stillinger and A. Rahman. J. Chem. Phys. 61. 4973 (1974).

[42] F. H. Stillinger. Philos. Trans. R. Soc. London Ser. B 278.97 (1977).

[43] E. Whalley, J. Chem. Phys. 63. 5205 (1975).
[44] C. A. Angell, E. D. Finch. L. A. Woolf, and P. Bach. J. Chem. Phys. 65, 3063 (1976)

[45] C. A. Angell, in: Water - A Comprehensive Treatise. Vol. 7. ed. by F. Franks. Plenum Press. New York 1980. in press.

[46] G. Harrison. The Dynamic Properties of Supercooled Liquids. p. $20 \mathrm{ff} .$, Academic Press. London 1976.

[47] C. A. Angell, J. Chem. Educ. 47. 583 (1970)

[48] M. Goldstein. J. Chem. Phys. 67. 2246 (1977).

[49] M. H. Cohen and G. S. Grest. Phys. Rev. B 20) 1077 (1979).

[50] C. A. Angell and K. J. Rao. J. Chem. Phys. 57. 470 (1972).

[51] M. G. Sceats. M. Stavola. and S. A. Rice. J. Chem. Phys. 70. 3927 (1979)

[52] F. P. Ricci, M. A. Ricci. and D. Rocca. J. Chem. Phys. 66. 5509 (1977).

[53] G. E. Walrafen. in: Water - A Comprehensive Treatise. Vol. 1. p. 151 ff.. ed. by F. Franks. Plenum Press. New York 1972 [54] R. J. Speedy and C. A. Angell. J. Chem. Phys. 65. 851 (1976).

[55] D. Kivelson, Faraday Symp. Chem. Soc. 11. 1 (1977).

[56] E. Lang and H.-D. Lüdemann. to be published.

(Eingegangen am 31. Januar 1980)

\title{
Rate and Equilibrium Data for the Complex Formation of Alkali Metal Ions with the Cryptand $(2,2,1)$ in Methanol
}

\author{
B. G. Cox
}

Chemistry Department, University of Stirling, Stirling FK9 4LA, Scotland

\author{
I. Schneider, H. Schneider
}

Max-Planck-Institut für Biophysikalische Chemie, D-3400 Göttingen, West-Germany

Komplexverbindungen / Reaktionskinetik

The dissociation rates of complexes between alkali metal ions and the macrobicyclic ligand 4,7,13,16,21-pentaoxa-1,10-diazabicyclo-(8,8.5)tricosane (cryptand- $(2,2,1)$ ) have been studied in methanol by stopped-flow experiments at various temperatures. The corresponding rates of formation were calculated using stability constants. Enthalpies and entropies of activation were compared with the corresponding quantities of complexation and discussed in terms of ionic size and ionic solvation. The specific dependence of decomplexation rate and stability constant on ionic radius [15] were found also for the corresponding enthalpies of activation and complexation, respectively, but the preference of $\mathrm{Na}^{+}$over $\mathrm{K}^{+}$is reversed. This fact together with the observation that the rate of dissociation of $\mathrm{Na}(2,2,1)^{+}$is enhanced by proton catalysis, led to the suggestion that the cavity radius of $(2,2,1)$ lies between the ionic radii of $\mathrm{Na}^{+}$and $\mathrm{K}^{+}$.

Die Dissoziationsgeschwindigkeit der Komplexe von Alkaliionen mit dem makrobicyclischen Liganden 4,7,13,16,21-Pentaoxa-1.10-diazabicyclo-18.8.5)-tricosan (2,2,1) wurde in Methanol mit einem .,stopped-flow"-Verfahren bei verschiedenen Temperaturen untersucht. Die Geschwindigkeitskonstante der Komplexbildung wurde aus derjenigen der Dissoziation mit Hilfe der Stabilitätskonstanten berechnet. Die Aktivierungsenthalpien und -entropien wurden mit den Reaktionsenthalpien und -entropien verglichen und die Einflüsse von Ionengröße und Ionensolvatation diskutiert. Die spezifische Abhängigkeit der Dissoziationsgeschwindigkeit und der Komplexstabilität vom Ionenradius [15] wird auch für die Aktivierungsenthalpie der Dissoziation und die Reaktionsenthalpie gefunden. jedoch mit vertauschter Reihenfolge von $\mathrm{Na}^{+}$und $\mathrm{K}^{+}$. Diese Eigenschaft und die Beobachtung, daß die Dissoziationsgeschwindigkeit von $\mathrm{Na}(2.2,1)^{+}$durch $\mathrm{Säure}$ beschleunigt wird, lassen vermuten, daß die Größe des Hohlraumradius von $(2,2,1)$ zwischen den Werten für die Radien von $\mathrm{Na}^{+}$und $\mathrm{K}$ liegt.

\section{Introduction}

Within the continually expanding group of macrocyclic and macrobicyclic ligands which form stable complexes with metal ions, macrobicyclic diazapolyethers (cryptands) are additionally characterized by their ability to form extremely stable inclusion complexes (cryptates) with alkali and alkaline earth metal ions $[1,2]$ which dissociate unusually slowly. These properties facilitate a thorough investigation of complex stability [3-9] and dissociation rate constants $[10-15]$. and, in addition, the determination of the thermodynamic functions for complex formation and for the activation process [16]. The simpler cryptands, in which the three bridges between the nitrogen atoms contain only one or two ether groups, display pronounced peak selectivities for those cations of the first or second groups of elements which are able to fill the ligand cavities, which in the complexed state are 